\title{
Outcome of Varicoceles Scrotal Sclerotherapy in Infertile Patients with Recurrent Varicocele
}

\author{
Mazen A Ghanem ${ }^{1,2 *}$, Essa A Adawi', Manal A Safan ${ }^{3}$ and Ashraf A Ghanem ${ }^{4}$ \\ ${ }^{1}$ Departments of Urology, Menoufia University, Egypt \\ 2Jazan University, Saudi Arabia \\ ${ }^{3}$ Medical Biochemistry, Menoufia University, Egypt \\ ${ }^{4}$ Gynaecology and Obstetrics Department, Mansoura University, Egypt
}

*Corresponding author: Mazen A Ghanem, Departments of Urology, Menoufia University, Cairo-New Cairo-Al Rehab city, Egypt, P.O. Box: 11841, Tel: +00201015046394, Fax:+20-2-26922829, E-mail: mazenghanem99@yahoo.co.uk

\begin{abstract}
Aims: To determine the efficacy of antegrade scrotal sclerotherapy (ASS) for the treatment of persistent or recurrent varicoceles in infertile men.

Patients and methods: A total of 54 patients with persistent or recurrent varicocele and impaired semen quality underwent ASS for the treatment of a varicocele. The parameters for evaluation every 6 months after redo surgery included semen parameters, serum levels of inhibin B, FSH, total testosterone, testicular volume, postoperative complications and spontaneous pregnancy rates. Twenty-four (24) control subjects with abnormal semen parameters, were randomly selected from untreated infertile varicocele patients.

Results: After a mean follow up of $32.66 \pm 1.7$ months, significant improvement was noted in mean sperm concentration, motility and morphology $(p<0.05)$. Also, a significant lowering in the percentage of sperm with abnormally thin head morphology was observed after redo surgery. A couple's chance of spontaneous pregnancy rates was higher and occurred in 20 cases (37\%). No significant changes in the mean serum inhibin $\mathrm{B}, \mathrm{FSH}$ and total testosterone levels were observed during follow up. No patient experienced recurrence, hydrocele or testicular atrophy.

Conclusions: Antegrade internal spermatic vein sclerotherapy is technically safe and effective for treatment of persistent or recurrent varicoceles. ASS can significantly improve seminal parameters in men with recurrent varicocele and may even result in increased chance of spontaneous pregnancy.
\end{abstract}

\section{Keywords}

Infertility, Sclerotherapy, Semen parameters, Inhibin B, Recurrent varicocele

\section{Introduction}

Varicocele is an andrological condition characterized by abnormal dilatation and tortuosity of the veins of the pampiniform plexus within the spermatic cord and is one of the most important causes of male fertility. Its prevalence is known to be about $22 \%$ in the general male population and $15 \%$ in adolescents. About forty percent of men with varicoceles associated with abnormal semen parameters [1,2]. Several studies confirmed an association between varicocelectomy and improvement of seminal parameters [3]. Moreover, recent randomized controlled trials (RCTs) showed the potential improvement also in the pregnancy rate in patients who did varicocelectomy in comparison with observation [2]. However, many procedures either surgical or percutaneous routes have provided effective treatment with recurrence rates reported at $1 \%-20 \%$ in the published literature $[4,5]$. The cause of recurrence is most frequently demonstrated by either retrograde or antegrade gonadal venography as collateralization of the gonadal vein and incompetent valves of the internal spermatic vein (ISV) [6-9].

The choice of the technique for recurrent varicocele repair and the procedure's impact on semen quality parameters and serum hormonal spermatogenic markers (total testosterone, FSH and inhibin B) are much debated. Many procedures have been used for recurrent varicocele treatment such as open spermatic vein ligation,

Citation: Ghanem MA, Adawi EA, Safan MA, Ghanem AA (2018) Outcome of Varicoceles Scrotal Sclerotherapy in Infertile Patients with Recurrent Varicocele. Int Arch Urol Complic 4:037. doi.org/10.23937/24695742/1510037

Received: March 15, 2018: Accepted: May 12, 2018: Published: May 14, 2018

Copyright: (c) 2018 Ghanem MA, et al. This is an open-access article distributed under the terms of the Creative Commons Attribution License, which permits unrestricted use, distribution, and reproduction in any medium, provided the original author and source are credited. 
laparoscopy, and microsurgery. However, all previous surgical strategies aimed at ligation of collateral veins that are inadequate to reduce varicocele recurrence $[6,8,10]$. On the other hand, percutaneous transcatheter embolization have been used as minimally invasive procedures, which allows detection of the internal spermatic vein and collateral veins that either been missed during varicocoelectomy or recanalized postoperatively [11,12].

The relevance of recurrent varicocele repair in assisted reproductive technologies (ART) and the pregnancy outcome is also still subject to debate because of the controversy in research findings $[13,14]$. The effective role of antegrade scrotal sclerotherapy (ASS) in infertile patients with varicocele have been studied and proved [15]. However, only few reports about its role in recurrent varicocele have been published [16]. In this study, we evaluate the treatment outcome of ASS in infertile patients with recurrent varicocele.

\section{Patients and Methods}

\section{Patients}

Fifty-four (54) infertile patients were diagnosed with abnormal semen parameters and identified as having persistent or recurrent varicocele ( 28 subinguinal, 12 high retroperitoneal ligation, 8 inguinal, and 6 laparoscopic) with a minimum postoperative follow-up of 6 months before a redo surgical repair, and who had a minimum six-month follow-up post redo repair [17]. Those 54 consecutive patients were referred to our $\mathrm{Di}$ vision of Andrology in order to undergo ASS. This study was approved by our local ethics committee and was conducted in accordance with the Declaration of Helsin$\mathrm{ki}$, and all the participants provided a written informed consent. Twenty-four (24) varicocele patients with abnormal semen parameters, who did not undergo any surgical intervention or medical treatment, were included as controls. Control subjects were randomly selected from untreated infertile varicocele patients. The mean age of control group was $32.91 \pm 1.2$ years (range 23 43).

\section{Inclusion and exclusion criteria}

The following criteria had to be included: Infertility persisting longer than 1 year despite regular, unprotected intercourse; and at least one abnormal semen parameters in the initial semen analysis plus semen analyses at 6 months after redo repair assessed by WHO guidelines [18]. Patients with other urogenital diseases (maldescended testis, infection, previous scrotal surgery), endocrinological and internal diseases were excluded from the study. All the studied group have a normal karyotyping, while the patient with genetic abnormalities (e.g., chromosomal abnormalities and $Y$ chromosome microdeletions) were excluded from the study. Also, no definite causes of infertility in partner such as anovulation, endometriosis, or tubal blockage.

\section{Clinical examination}

Varicocele was diagnosed in men with fertility problems. All patients underwent physical examination in an upright position with the aid of the Valsalva maneuver. Clinical varicocele was graded according to the recommendations of WHO [19].

\section{Scrotal ultrasonography}

These patients underwent Duplex Doppler ultrasonography of the scrotum in standing and supine position with Valsalva maneuver which was performed before the procedure and 6 months after sclerotherapy. Varicocele was considered persistent or recurrent both clinically and by detection of venous reflux by Duplex Doppler ultrasonography. The testicular volume based on ultrasound was calculated using the formula volume (V) $=0.71$ (length $\times$ width $\times$ depth). When no ultrasound volume was available, the testicular volume was calculated using the formula volume $(V)=1 / 6$ length width [20]. The normal total testicular volume was defined as $32 \mathrm{~mL}$ or more [21].

\section{Hormonal analysis}

Serum inhibin B, FSH, and total testosterone levels were assayed in blood samples drawn in the morning before the sclerotherapy and 6 months after the sclerotherapy. Serum inhibin B was measured by enzyme immunoassay according to the method previously described by Lambert-Messerlian, et al. [22] and Groome, et al. [23]. The reference range for serum inhibin was taken as 113-389 pg/mL. Serum concentrations of FSH and total testosterone were measured by an automated chemiluminescence system $[24,25]$. The reference range for both serum total testosterone and FSH were $3.8-9.7 \mathrm{ng} / \mathrm{mL}$; $2.9-8.4 \mathrm{mlU} / \mathrm{L}$, respectively.

\section{Semen analysis}

Semen analysis was performed according to the 2010 WHO criteria: A sperm count $\leq 15$ million spermatozoa/mL and a percentage of progressive motility $\leq 32 \%$ ). Sperm morphology was assessed according to David's modified classification and the lower reference value for normal sperm was $15 \%$ [26]. Samples were obtained by masturbation after 2-5 days of sexual abstinence [27]. The data of semen analysis in each patient are the mean of 2 evaluations performed within 6 months before and after treatment by a single evaluator in both evaluations.

The Antegrade scrotal sclerotherapy (ASS) procedure was performed according to the technique described by Tauber and Johnsen [28], Di Bisceglie, et al. [29], Ghanem, et al. [15] and Alessandro C, et al. [30].

\section{Evaluation of the couples}

Baseline evaluation at follow up of the couples con- 
sisted of 3-months intervals visits for a period of 12 months. Spontaneous pregnancy data were collected. An ART procedure including intracytoplasmic sperm injection (ICSI), in vitro fertilization (IVF) and intrauterine insemination (IUI) for conception was determined by the presence of serum HCG of $>20$ IU on day 14 following embryo transfer, followed by a 2 months scan for presence of a foetal heartbeat.

\section{Statistical analysis}

The data were analyzed with the statistical package for social sciences, version 20, for windows software (SPSS Inc, Chicago, Illinois). P values $<0.05$ were considered statistically significant when examining the comparison of variables in two different groups. Results are expressed as mean \pm SEM. The statistical significance of any change in the serum hormonal values was tested using the spearman rank correlation.

\section{Results}

A total of 54 patients with recurrent varicocele underwent radiological sclerotherapy of the internal spermatic vein; all the patients had a technically successful antegrade sclerotherapy (ASS), as confirmed by disappearance of the varicocele both clinically and by Doppler ultrasonography. The mean varicocele recurrence time for the patients was 14.81 months (range: 8-22 months) after the initial treatment. All patients with recurrent varicoceles who underwent redo varicocelectomy had palpable left sided varicocele, where 52 (96\%) patients were grading I and $2(4 \%)$ were grade II. The mean age of this group at redo repair was 33.78 \pm 1.9 years (range $21-43$ ). The mean post redo repair follows up period was $32.66 \pm 1.7$ months (range, 18-58 months) (Table 1).

The preoperative and postoperative semen analysis after redo surgery using ASS showed a significant improvement in sperm concentration (14.24 $\pm 1.3 \times 10^{6} /$ $\mathrm{ml}$ vs. $\left.24.47 \pm 1.2 \times 10^{6} / \mathrm{ml}, \mathrm{p}<0.04\right)$ and progressive motility $(24.67 \pm 1.9 \%$ vs. $36.48 \pm 1.1 \%, p<0.02)$. Also, significant changes in normal sperm morphology were observed ( $14.17 \pm 1.5 \%$ vs. $28.76 \pm 1.2 \%, p<0.02)$. The mean percentage of sperm with an abnormally thin head was significantly lower after 6 months treatment than at basal examination $(7.98 \pm 0.3 \%$ vs. $15.46 \pm 0.2 \%, p<$ 0.03 , respectively). The mean multiple anomalies index was significantly lower when comparing six months treatment with basal examination $(1.85 \pm 0.2$ vs. $1.96 \pm 0.1$, $p<0.002$, respectively) (Table 2). A significant increase in semen parameters was observed in 39 patients (72\%).

At the base line, the mean serum total testosterone, FSH and inhibin B levels were $7.81 \pm 0.2 \mathrm{ng} / \mathrm{mL}, 8.56 \pm$ $0.3 \mathrm{mIU} / \mathrm{mL}$ and $146.62 \pm 2.9 \mathrm{pg} / \mathrm{mL}$, respectively. There were no any significant changes in any of these hormonal levels after redo surgery using ASS (Table 2). Also, no significant changes in right and left testicular volume was observed after ASS during 6 months follow up period (right: $18.89 \pm 0.5$ vs. $19.48 \pm 0.4 \mathrm{~mL}$; left: $19.11 \pm 0.5$ vs. $18.97 \pm 0.4 \mathrm{~mL} ; p>0.05$ ).

In the control group, no significant variations in seminal parameters were observed 6 months after basal examination (sperm concentration, $14.13 \pm 0.7$ vs. $14.14 \pm$ $0.7 \times 10^{6} / \mathrm{mL}$; progressive motility, $24.29 \pm 1.4$ vs. 25.08 $\pm 1.3 \%$; normal sperm morphology, $14.79 \pm 0.5$ vs. 14.29 $\pm 0.5 \%$; abnormal thin head, $14.04 \pm 0.5$ vs. $13.25 \pm 0.4 \%$; multiple anomalies index, $1.79 \pm 0.1$ vs. $1.71 \pm 0.2$. A significant difference was found in the seminal parameters (sperm concentration, progressive motility, normal sperm morphology, abnormal thin head and multiple anomalies index) in the treated subjects in comparison with controls $(p<0.05)$. No significant changes in testicular volume was observed during 6 months follow up period (right: $18.89 \pm 0.5$ vs. $19.48 \pm 0.5 \mathrm{~mL}$; left: $19.11 \pm$ 0.5 vs. $18.98 \pm 0.4 \mathrm{~mL} ; \mathrm{p}>0.05)$.

Table 1: Preoperative patient's demographic data.

\begin{tabular}{|l|l|}
\hline Number of patients & 54 \\
\hline Mean age (years) & $33.78 \pm 1.9$ \\
\hline Mean follow-up (months) & $32.66 \pm 1.7$ \\
\hline Mean latency time after surgery (months) & $14.81 \pm 0.6$ \\
\hline Previous surgical approaches & \\
\hline Subinguinal ligation & $28(52 \%)$ \\
\hline High retroperitoneal ligation & $12(22 \%)$ \\
\hline Inguinal ligation & $8(15 \%)$ \\
\hline Laparoscopic varicocelectomy & $6(11 \%)$ \\
\hline Varicocele & \\
\hline Grade I & $52(96 \%)$ \\
\hline Grade II & $2(4 \%)$ \\
\hline
\end{tabular}

Table 2: Changes in the Semen parameters and hormonal levels before and after 6 months follow up in both post redo varicocelectomy patients and control groups.

\begin{tabular}{|c|c|c|c|c|c|c|}
\hline \multirow[t]{2}{*}{ Parameter } & \multicolumn{3}{|c|}{ Patient group } & \multicolumn{3}{|l|}{ Control group } \\
\hline & Before AS & After AS & ${ }^{ \pm P}$ value & Before 6 months & After 6 months & ${ }^{*} \mathbf{P}$ value \\
\hline Semen concentration (million/ml) & $14.24 \pm 1.3$ & $24.47 \pm 1.2$ & 0.04 & $14.14 \pm 0.7$ & $14.13 \pm 0.7$ & 0.001 \\
\hline Motility (\%) & $24.67 \pm 1.9$ & $36.48 \pm 1.1$ & 0.02 & $25.08 \pm 1.4$ & $24.29 \pm 1.3$ & 0.001 \\
\hline Morphology (\% of normal) & $14.17 \pm 1.5$ & $28.76 \pm 1.2$ & 0.02 & $14.29 \pm 0.5$ & $14.79 \pm 0.5$ & 0.007 \\
\hline$\%$ Thin head & $15.46 \pm 0.2$ & $7.98 \pm 0.3$ & 0.03 & $13.25 \pm 0.4$ & $14.04 \pm 0.5$ & 0.04 \\
\hline Multiple Anomalies Index & $1.96 \pm 0.1$ & $1.85 \pm 0.2$ & 0.002 & $1.71 \pm 0.2$ & $1.79 \pm 0.1$ & 0.04 \\
\hline Inhibin B (pg/mL) & $146.62 \pm 2.9$ & $145.64 \pm 2.8$ & 0.12 & $142.99 \pm 5.3$ & $141.17 \pm 4.9$ & 0.71 \\
\hline $\mathrm{FSH}(\mathrm{mIU} / \mathrm{mL})$ & $8.56 \pm 0.3$ & $8.67 \pm 0.2$ & 0.11 & $8.51 \pm 0.4$ & $8.79 \pm 0.5$ & 0.36 \\
\hline Testosterone (ng/mL) & $7.81 \pm 0.2$ & $7.98 \pm 0.1$ & 0.89 & $7.97 \pm 0.3$ & $7.89 \pm 0.2$ & 0.27 \\
\hline
\end{tabular}

${ }^{ \pm} \mathrm{P}$ value (Comparison between two patient groups); $\mathrm{P}$ value (Comparison between patient group after ASS and control group). 
Also, in the control group no significant variations in hormonal levels were observed 6 months after basal examination (inhibin B, $141.17 \pm 4.9$ vs. $142.99 \pm 5.3 \mathrm{pg} /$ $\mathrm{mL}$; $\mathrm{FSH}, 8.79 \pm 0.5 \%$ vs. $8.51 \pm 0.4 \mathrm{mIU} / \mathrm{mL}$; total testosterone, $7.89 \pm 0.2 \%$ vs. $7.97 \pm 0.3 \mathrm{ng} / \mathrm{mL}$.

By a mean of $8.1 \pm 3.1$ months after redo surgery, 20 (37)\% of couples had achieved spontaneous pregnancy. Where, men who achieve a spontaneous conception had a higher significant improvement in the semen parameters than those that did not. An additional (9) $32 \%$ of 28 couples achieved pregnancy via ART (ICSI, IVF, IUI) with a mean of $18.3 \pm 6.6$ months after ASS procedure. The chance of achieving clinical pregnancy rates $(38 \%$, $33 \%$ and $22 \%$ in ICSI, IUI and IVF, respectively) and live birth rates $(31 \%, 16 \%$, and $11 \%$ in ICSI, IUI and IVF, respectively) by ART procedure were achieved.

Six patients suffered spermatic cord inflammation that resolved with antibiotics and one case had a superficial wound infection. No patient developed a hydrocele after surgery. No patient experienced another recurrence or testicular atrophy.

\section{Discussion}

Varicocele is a pathological condition which is clearly associated with infertility and impaired testicular function. A recent meta-analysis of published literature has shown that varicocele repair significantly improves sperm parameters and quality. However, persistent or recurrent varicocele after failed varicocelectomy is still a significant complication in infertile patients $[5,6,31]$.

A redo varicocelectomy in infertile patients is a matter of controversy. Where many surgeons prefer subinguinal microscopic repair of recurrent varicocele based on the higher success rates and a lower incidence of recurrence of primary open repair [32,33]. However, still redo surgery associated with an increase the incidence of hydrocele formation, testicular artery injury, testicular volume loss and varicocele recurrence [17]. This mainly due to the anatomical disturbance of both the blood supply and lymphatic drainage to the ipsilateral testicle during the primary repair and therefore more prone for further injury during redo surgery. For this reason, some practitioners have favored the use of radiographic percutaneous treatment, feeling this procedure is safer and thus the therapeutic modality of choice $[11,34]$. In this current study, the decision is to perform a redo varicocelectomy with ASS in a group of infertile patients with abnormal semen parameters.

However, data on the effect of antegrade sclerotherapy treatment on semen parameters in patients with recurrent varicocele are limited [16]. In the present study; this technique has proved to be effective in this group of patients in terms of improvement of the semen parameters. Also, there is a significant decrease in the proportion of spermatozoa with an abnormally thin head. In contrast, Gazzera, et al. [35] did not observe any sig- nificant differences in sperm morphology. At the same time, there is an increased incidence of the chance of spontaneous pregnancies in couples up to $37 \%$. So, redo repair improved patient semen parameters to a level that may reduce the need for ARTs or sperm retrieval procedures. Also, in case of no spontaneous pregnancy the sperm improvement allowed an upgrading of artificial reproductive techniques, from ICSI to IUI and IVF $[36,37]$. In this group of patients, ICSI showed a significantly better pregnancy rate than IUI and IVF $[38,39]$. So, in patients who still needed ART for conception, a redo repair was found to increase the pregnancy rates and live birth rates.

Varicocele in infertile men is generally associated with pathological changes in the seminiferous tubule structure, impaired spermatogenesis, and hypogonadism. It has been shown that varicocelectomy significantly increases serum total testosterone levels and inhibin $B$ concentrations in infertile men with hypogonadism [40]. Also, non-obstructive azoospermia (NOA) patients may show ejaculated spermatozoa and significantly decrease in serum FSH level after a retrograde internal spermatic vein embolization of a left side varicocele [41]. In the present study, we did not observe significant changes in serum total testosterone, $\mathrm{FSH}$ and inhibin B concentrations after ASS. In contrast, in men with severe oligoasthenoteratozoospermia (OAT), ASS was associated with a significant increase in inhibin $B$ levels and a significant decrease in FSH levels [15]. This discrepancy may be due to the fact that the serum inhibin $\mathrm{B}$ and FSH levels were in the normal range in the current study, which suggests that spermatogenesis was not strongly altered. Also, there were no major Sertoli cell disorders and Leydig cell dysfunction in the population of study.

ASS, beside many advantages mentioned by Ghanem, et al. [15] has the advantageous that a phlebography performed before procedure allows the identification of the patient's venous drainage pathway of the testis and cause of recurrent varicocele and subsequent planning in order to ensure a safe procedure. Also, spermatic cord dissection was avoided, and the vas deferens and deferential vessels, cremasteric muscle, and a majority of the lymphatics and arteries were preserved as much as possible. So, ASS can be advocated as a safe and successful option in redo cases which also was documented by Mazzoni, et al. [16] although a small percentage of cases in this current study were noted to develop spermatic cord inflammation, but without unwanted implications in the fertility of such group of patients. Treatment with percutaneous embolization (PE) was also documented to be the least cost-effective approach and is best used only in cases of surgical failure in the era of the management of the varicocele-associated infertility [42].

Although many urologists recommend radiographic retrograde embolization as the safest form of redo re- 
pair, this method has $6-20 \%$ recurrence rates [5,10-12]. In contrast to our study, there were no further recurrences (during this relatively long follow up) after ASS in this study. Also, coils are still widely used to embolize the testicular veins in these procedures, which carry the risk of systemic migration of coils and cause ischemic testicle $[43,44]$. In addition, the details of the retrograde embolization procedure differ among institutions. At the same time, embolization requires a physician with experience in interventional radiology $[45,46]$.

Limitations of this study are the small cohort size. Despite the small number of patients included, however, this study is one of the largest series of its kind and when compared with most other recurrent varicocele studies. Also, this study is one of the first of its kind for improvements in semen parameters and conception rate following recurrent varicocele repair using ASS.

\section{Conclusions}

In conclusion, this study shows that antegrade scrotal sclerotherapy is an effective and safe procedure for treatment of patients with recurrent varicoceles. Also, it is associated with improvement in sperm parameters and increase in pregnancy rates in infertile patients. Therefore, this method should be also considered for such cases, even in cases in which the cause of recurrent varicocele is not evident. Meanwhile, more detailed studies should be further done in order to justify its superiority over other repeat surgery in recurred varicocele.

\section{Acknowledgments}

This article was not funded by organization nor had any financial relationships with any organization to conduct this study. Also, the authors declare that they have no conflict of interest.

\section{Conflict of Interest}

None declared.

\section{Author Contributions}

Ghanem Mazen A: Performed the surgical procedures.

Adawi Essa A: Assistant in the surgical procedures.

Safan Manal A: Performed the laboratory analysis.

Ghanem Ashraf A: Performed and monitored the ART procedures and pregnancy outcome.

\section{All Previous Authors}

Participated in the protocol design and collection and analysis of the data of this study and sequence manuscript writing and editing. All authors read and approved the final manuscript.

\section{References}

1. Jungwirth A, Giwercman A, Tournaye H, Diemer T, Kopa
Z, et al. (2012) European association of urology guidelines on male infertility: The 2012 update. Eur Urol 62: 324-332.

2. Kroese AC, de Lange NM, Collins J, Evers JL (2012) Surgery or embolization for varicoceles in subfertile men. Cochrane Database Syst Rev 10.

3. Brannigan RE (2017) Introduction: Varicoceles: A contemporary perspective. Fertil Steril 108: 361-363.

4. Niedzielski J, Paduch D (2001) Recurrence of varicocele after high retroperitoneal repair: Implications of intraoperative venography. J Urol 165: 937-940.

5. Sze D, Kao J, Frisoli J, McCallum S, Kennedy W, et al. (2008) Persistent and recurrent postsurgical varicoceles: Venographic anatomy and treatment with N-butyl cyanoacrylate embolization. J Vasc Interv Radiol 19: 539-545.

6. Murray R, Mitchell S, Kadir S, Kaufman S, Chang R, et al. (1986) Comparison of recurrent varicocele anatomy following surgery and percutaneous balloon occlusion. J Urol 135: 286-289.

7. Franco G, Leonardo C (2002) Is selective internal spermatic venography necessary in detecting recurrent varicocele after surgical repair? Eur Urol 42: 192-193.

8. Libman J, Segal R, Baazeem A, Boman J, Zini A (2010) Microanatomy of the left and right spermatic cords at subinguinal microsurgical varicocelectomy: Comparative study of primary and redo repairs. Urology 75: 1324-1327.

9. Kyung Hyun M, Suk Ju C, Kun Suk K, Seonghun P, Sungchan P (2012) Recurrent varicoceles: Causes and treatment using angiography and magnification assisted subinguinal varicocelectomy. Yonsei Med J 53: 723-728.

10. Grober E, Chan P, Zini A, Goldstein M (2004) Microsurgical treatment of persistent or recurrent varicocele. Fertil Steril 82: 718-722.

11. Punekar S, Prem A, Ridhorkar V, Deshmukh H, Kelkar A (1996) Post-surgical recurrent varicocele: Efficacy of internal spermatic venography and steel-coil embolization. $\mathrm{Br} \mathrm{J}$ Urol 77: 124-128.

12. Kim J, Shin J, Yoon H, Ko G, Gwon D, et al. (2012) Persistent or recurrent varicocoele after failed varicocoelectomy: Outcome in patients treated using percutaneous transcatheter embolization. Clin Radiol 67: 359-365.

13. Baazeem A, Belzile E, Ciampi A, Dohle G, Jarvi K, et al. (2011) Varicocele and male factor infertility treatment: A new meta-analysis and review of the role of varicocele repair. Eur Urol 60: 796-808.

14. Nevoux P, Mitchell V, Chevallier D, Rigot J, Marcelli $F$ (2011) Varicocele repair: Does it still have a role in infertility treatment? Curr Opin Obstet Gynecol 23: 151-157.

15. Ghanem M, Safan M, Ghanem A, Dohle G (2011) The role of varicocele sclerotherapy in men with severe oligo-astheno-teratozoospermia. Asian J Androl 13: 867-871.

16. Mazzoni G, Minucci S, Gentile V (2002) Recurrent varicocele: Role of antegrade sclerotherapy as first choice treatment. Eur Urol 4: 614-618.

17. Glassberg K, Bandalato G, Poon S, Mercado M, Raimondi $P$, et al. (2011) Evaluation and management of the persistent/recurrent varicocele. Urology 77: 1194-1198.

18. World Health Organization (2010) WHO laboratory manual for the examination and processing of human semen. ( $\left.5^{\text {th }} \mathrm{edn}\right)$.

19. World Health Organization (1993) Manual for the standardized investigation and diagnosis of the infertile couple. Cambridge University Press, Cambridge. 
20. Chipkevitch E, Nishimura R, Tu DGS, Galea-Rojas M (1996) Clinical measurement of testicular volume in adolescents: Comparison of the reliability of 5 methods. J Urology 156: 2050-2053.

21. Schiff JD, Li PS, Goldstein M (2004) Correlation of ultrasonographic and orchidometer measurements of testis volume in adults. BJU Int 93: 1015-1017.

22. Lambert-Messerlian G, Hall J, Sluss P (1994) Relatively low levels specific two-site enzyme immunoassay. J Clin Endocrinol Metab 79: 45-50.

23. Groome N, Illingrowth $P$, Brien M (1996) Measurement of dimeric inhibin $\mathrm{B}$ throughout the human menstrual cycle. $\mathrm{J}$ Clin Endocrinol Metab 81: 1401-1405.

24. Pierik F, Vreeburg J, Stijnen T, De Jong F, Weber R (1998) Serum inhibin $B$ as a marker of spermatogenesis. J Clin Endocrinol Metab 83: 3110-3114.

25. Vermeulen A, Verdonck L, Kaufman M (1999) A critical evaluation of simple methods for the estimation of free testosterone in serum. J Clin Endocrinol Metab 84: 3666-3672.

26. Auger J, Eustache F, Ducot B, Blandin T, Daudin M, et al. (2000) Intra- and inter-individual variability in human sperm concentration, motility and vitality assessment during a workshop involving ten laboratories. Hum Reprod 15: 2360-2368.

27. Marmar J, Kim Y (1994) Subinguinal microsurgical varicocelectomy: A technical critique and statistical analysis of semen and pregnancy data. J Urol 152: 1127-1132.

28. Tauber R, Johnsen N (1994) Antegrade scrotal sclerotherapy for the treatment of varicocele: Technique and late results. J Urol 151: 386-390.

29. Di Bisceglie C, Fornengo R, Grosso M, Gazzera C, Mancini A, et al. (2003) Follow-up of varicocele treated with percutaneous retrograde sclerotherapy: Technical, clinical and seminal aspects. J Endocrinol Invest 26: 1059-1064.

30. Alessandro C, Gianluca G, Mattia C, Marta R, Mariangela $M$, et al. (2016) Antegrade scrotal sclerotherapy of internal spermatic veins for varicocele treatment: Technique, complications, and results. Asian J of Androl 18: 292-295.

31. Rotker K, Sigman M (2016) Recurrent varicocele. Asian J Androl 18: 229-233.

32. Beutner S, May M, Hoschke B, Helke C, Lein M, et al. (2007) Treatment of varicocele with reference to age: A retrospective comparison of three minimally invasive techniques. Surg Endosc 21: 61-65.

33. Evers J, Collin J (2004) Surgery or embolization for varicoceles in subfertile men. Cochane Database Syst Rev.

34. Guevara CJ, El-Hilal AH, Darcy MD (2015) Percutaneous antegrade varicocele embolization via the testicular vein in a patient with recurrent varicocele after surgical repair. Cardiovasc Intervent Radiol 38: 1325-1329.

35. Gazzera C, Rampado O, Savio L, Di Bisceglie C, Manieri C, et al. (2006) Radiological treatment of male varicocele: Technical, clinical, seminal and dosimetric aspects. Radiol Med 111: 449-458.

36. Gat Y, Bachar G, Everaert K, Levinger U, Gornish M (2005) Induction of spermatogenesis in azoospermic men after internal spermatic vein embolization for the treatment of varicocele. Hum Reprod 20: 1013-1017.

37. Osmonov D, Van der Horst, Weyel T, Danilevicius M, Braun $P$, et al. (2006) Induction of spermatogenesis in patients with non-obstructive azoospermia after antegrade sclerotherapy. Aktuelle Urol 37: 132-137.

38. Bakos H, Thompson J, Feil D, Lane M (2007) Sperm DNA damage is associated with assisted reproductive technology pregnancy. Int J Androl 31: 518-526.

39. Mangoli V, Dandekar S, Desai S, Mangoli R (2008) The outcome of ART in males with impaired spermatogenesis. J Hum Reprod Sci 1: 73-76.

40. Fisch H, Hyun G (2012) Varicocele repair for low testosterone. Curr Opin Urol 22: 495-498.

41. D'Andrea S, Giordano AV, Carducci S, Sacchetti L, Necozione S, et al. (2015) Embolization of left spermatic vein in non-obstructive azoospermic men with varicocele: Role of FSH to predict the appearance of ejaculated spermatozoa after treatment. J Endocrinol Invest 38: 785-790.

42. Kovac JR, Fantus J, Lipshultz LI, Fischer MA, Klinghoffer Z (2014) Cost-effectiveness analysis reveals microsurgical varicocele repair is superior to percutaneous embolization in the treatment of male infertility. Can Urol Assoc J 8: E619-E625.

43. Nabi G, Asterlings S, Greene D, Marsh R (2004) Percutaneous embolization of varicoceles: Outcomes and correlation of semen improvement with pregnancy. Urology 63: 359-363.

44. Storm D, Hogan M, Jayanthi V (2010) Initial experience with percutaneous selective embolization: A truly minimally invasive treatment of the adolescent varicocele with no risk of hydrocele development. J Pediatr Urol 6: 567-571.

45. Makris G, Efthymiou E, Little M, Boardman P, Anthony S, et al. (2018) Safety and effectiveness of the different types of embolic materials for the treatment of testicular varicoceles: A systematic review. Br J Radiol 12: 20170445.

46. Li L, Zeng XQ, Li YH (2009) Digital subtraction angiography-guided percutaneous transcatheter foam sclerotherapy of varicocele: A novel tracking technique. AJR Am J Roentgenol 193: 978-980. 